\title{
Role of EDAPTMS-Functionalized Silica Derived from Rice Husk Ash in the Adsorption Kinetics of $\mathrm{Cu}$ (II), $\mathrm{Cr}(\mathrm{III})$, and $\mathrm{Pb}(\mathrm{II})$
}

\author{
Is Fatimah*, Tesha Yuliani, Dian Rianti \\ Chemistry Department, Islamic University of Indonesia, Kampus Terpadu UII, \\ Jl. Kaliurang Km 14, Sleman, Yogyakarta, Indonesia
}

Received: $8^{\text {th }}$ October 2017; Revised: $27^{\text {th }}$ January 2018; Accepted: $29^{\text {th }}$ January 2018; Available online: $11^{\text {st }}$ June 2018; Published regularly: $1^{\text {st }}$ August 2018

\begin{abstract}
In the present work, synthesis of (3-ethylene diamino propyl)-trimethoxysilane (EDAPTMS)functionalized silica prepared from rice husk ash (RHA) and its adsorptivity of $\mathrm{Cu}$ (II), $\mathrm{Cr}$ (III), and $\mathrm{Pb}$ (II) in an aqueous solution was investigated. The EDAPTMS-functionalized silica was prepared by destruction of RHA with $4 \mathrm{M} \mathrm{NaOH}$ solution followed by functionalization by using the sol-gel method. The interaction was engaged by mixing EDAPTMS with silica gel in an acid condition followed by aging. The gel obtained from the procedure was analyzed by using X-ray diffraction (XRD), infrared spectroscopy (FTIR), and a surface area analyzer (SAA). Effect of EDAPTMS content on the material character and adsorption capability are the focuses of the study. The adsorption study was conducted in a batch adsorption system for $\mathrm{Cu}(\mathrm{II}), \mathrm{Cr}(\mathrm{III})$, and $\mathrm{Pb}(\mathrm{II})$ mixed solution and metal ion analyses were performed by atomic absorption spectrophotometry. The results showed that enhancement of physicochemical character was obtained after modification Based on the quantitative analysis of each metal, the kinetics of adsorption of a single solution of each ion and mixed solutions were studied. as shown by the increasing specific surface area as well as the increasing adsorption rate of the metal ions along increasing EDAPTMS content. Langmuir and Freundlich models were utilized for the kinetic study. Adsorption selectivity and adsorption kinetics were found to be strongly influenced by ionic coordination bonding with metal ions. The interpretation of the kinetic models showed the fitness of the Freundlich model for all metal ions. Copyright (C) 2018 BCREC Group. All rights reserved
\end{abstract}

Keywords: Adsorption; Functionalized Silica; Kinetic Model; Rice Husk Ash

How to Cite: Fatimah, I., Yuliani, T., Rianti, D. (2018). Role of EDAPTMS-Functionalized Silica Derived from Rice Husk Ash in the Adsorption Kinetics of $\mathrm{Cu}(\mathrm{II}), \mathrm{Cr}$ (III), and $\mathrm{Pb}$ (II). Bulletin of Chemical Reaction Engineering \& Catalysis, 13 (2): 331-340 (doi:10.9767/bcrec.13.2.1587.331-340)

Permalink/DOI: https://doi.org/10.9767/bcrec.13.2.1587.331-340

\section{Introduction}

Heavy metal contamination caused by industry and man-made sources is an important issue in environmental monitoring. In recent years, certain industrial activities, including

* Corresponding Author.

E-mail: isfatimah@uii.ac.id (I. Fatimah) the combustion of fossil fuels, the electronics and textile industries, the leather industry and craft, the refining of oil and the manufacturing of paint, pulp and paper, and batteries could have resulted in the potential release of toxic metals, such as copper $(\mathrm{Cu})$, lead $(\mathrm{Pb})$, and chromium $(\mathrm{Cr})$, either in the soil or in aquatic environments. In order to minimize the accumulation of toxic metal contamination in higher-level 
anthropogenic systems, the reduction and control of metal contamination in aquatic systems have been widely investigated. Moreover, some adsorption techniques are considered importantly and are widely used within a total metal monitoring and evaluation process. Such processes show that the presence of metals is usually contained in multicomponent systems, and as such, a selective adsorption of certain heavy metals is required. Among such inorganic materials, silica is a stable adsorbent widely recognized for heavy metal adsorption. Although silica is chemically inert, it allows some modifications to improve adsorption capability. Some studies have reported silica modification by creating a mesoporous structure of silica as well as surface modification with specific functional groups having an affinity to chemically bond to metal. For the last-mentioned technique, surface modification of silica by using an amine functional group consisting of aminosilane compounds was employed for the silica functionalization as the selective adsorbent [1-4]. Amine modified silicas have been reported as selective adsorbent for metals as well as $\mathrm{CO}_{2}$ [5-12].

On the other hand, silica synthesis can be conducted by using a variety of silica sources, and one of these is from agricultural waste: rice husk ash. Considering that rice husk ash is very abundant in Indonesia and is present as agriculture residue, the use of rice husk as a source for silica synthesis has been reported as feasible in much of the literature [13-15]. Furthermore, in order to accelerate the adsorption of some metal ions, the development of aminegrafted silica by using rice husk ash as the silica source is conducted in this research. The work aims to prepare and characterize aminegrafted silica and its profile in adsorption of heavy metal in which $\mathrm{Cu}$ (II), $\mathrm{Cr}$ (III), and $\mathrm{Pb}$ (II) have been selected as models. Silica surface functionalization was performed by ethylene diamine aminopropyl trimethoxy silane (EDAPTMS) to create a surface that is active in metal-amine chemisorption. A study on the kinetics of adsorption of a single metal solution and mixed metal solutions was employed to evaluate the trend of adsorbent selectivity.

\section{Material and Methods}

\subsection{Materials}

Rice husk ash was obtained by burning rice husk at $700{ }^{\circ} \mathrm{C}$ for 2 hours. The rice husk was collected from domestic agricultural waste in Sleman District, Special Region of Yogyakarta (DIY) Province. Some chemicals, such as: $\mathrm{NaOH}, \mathrm{HCl}$, dimethyl suphoxide (DMSO), iso- propanol, $\mathrm{CuCl}_{2}, \mathrm{CrCl}_{3}$, and $\mathrm{PbCl}_{2}$, were obtained from Merk-Millipore, Germany, while ethylene diamine aminopropyl trimethoxy silane (EDAPTMS) was purchased from SigmaAldrich.

\subsection{Preparation and characterization}

Silica extraction from rice husk ash (RHA) was conducted using the same method as reported earlier [16]. First, RHA was washed with $\mathrm{HCl} 1 \mathrm{M}$ and was filtered off. The residue obtained by the process was then diluted in $\mathrm{NaOH} 4 \mathrm{M}$ and aged overnight before being titrated by $\mathrm{HCl}$ until the $\mathrm{pH}$ was equal to 8 . The gel obtained from the process is called silica gel. For the silica preparation, the gel was dried at $100{ }^{\circ} \mathrm{C}$ for 5 hours to obtain a powder. For the preparation of ethylene diamine aminopropyl trimethoxy silane-modified silica (EDAPTMS-Si), the gel was added with EDAPTMS. The synthesis of (EDAPTMS-Si) was prepared by mixing silica gel obtained with an ethylene diamine aminopropyl trimethoxy silane (APTMS) solution in DMSO: isopropanol until the ratio of APTMS to silica weight was reached. The varied APTMS weight ratios were 1,2 , and $5 \% \mathrm{wt}$, and from this variable the obtained samples were designated as EDAPTMSSi-1; EDAPTMS-Si-2 and EDAPTMS-Si-5. The mixture was stirred overnight at room temperature before being heated in an oven at 90 ${ }^{\circ} \mathrm{C}$. Both modified and unmodified silica were characterized by XRD measurement with $\mathrm{Cu}$ Ka radiation at a $2 \theta$ range of $3-65^{\circ}, \mathrm{N}_{2}$ adsorption-desorption profile and Fourier-Transform Infrared (FTIR) analysis. A Shimadzu X6000 XRD instrument, Quantachrome NOVA 2000 and Nicolet Avatar FTIR spectrophotometer instruments were utilized for the characterizations. $\mathrm{N}_{2}$ adsorption isotherms of the samples were measured at liquid nitrogen temperature and the specific surface areas were calculated using the BET method.

\subsection{Adsorption experiment}

For selective adsorption, aqueous solutions of $\mathrm{Cu}$ (II), $\mathrm{Cr}$ (III), and $\mathrm{Pb}$ (II) in each single solution and in mixtures with varied concentrations were prepared. Approximately $20 \mathrm{mg}$ adsorbent was charged into $50 \mathrm{~mL}$ adsorbate with continuous stirring for 1 hour. In order to study the kinetics of adsorption, a series of the experiments were performed at varied times of adsorption, initial concentration of metal and varied $\mathrm{pH}$ of the solution. For the varied $\mathrm{pH}$ of the solution, the metal solution was prepared under a buffer solution condition. The samples 
from the adsorption experiments were collected by filtration and the metal concentration in the samples was determined by atomic absorption spectroscopy (AAS).

\section{Results and Discussion}

\subsection{Characterization of materials}

Modification of silica obtained from RHA by using EDAPTMS is aimed at improving selectivity to adsorb metal ions. The modification itself was conducted in a sol-gel mechanism according to previous research; the hypothesized reaction in the synthesis material and the in- teraction between the material and the $\mathrm{Pb}$ ion is presented in Figure 1 [17].

EDAPTMS will bond to silica by methanolysis during aging and drying. Due to organic molecule attachments in the silica structure, some physicochemical characters are theoretically changed. Therefore, analyses related to the change of the surface profile as well as crystallinity were studied. A nitrogen adsorption-desorption profile of EDAPTMS-Si compared with Si from RHA is depicted in Figure 2.

From the pattern, it is concluded that all adsorption-desorption pattern obeys type IV re-<smiles>C#[W]OCCCCOC(C)(OC)OCCCNCCS</smiles>

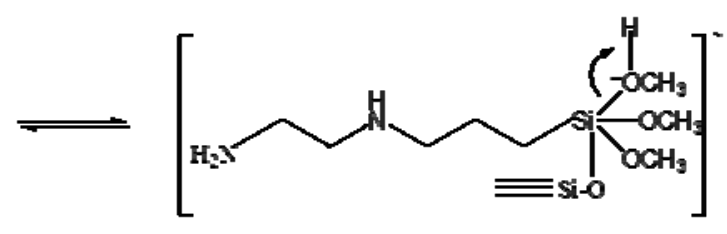

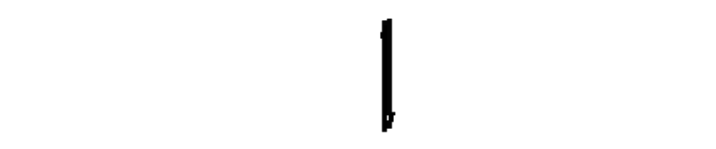<smiles>C#[W]OC(CO)(OC)OC</smiles>

A

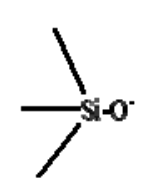<smiles>C=COC(CCCNCCN)(OC)OC</smiles><smiles>COCCO</smiles><smiles>C#COC(CCCNCCN)(OC)OC#C</smiles><smiles></smiles><smiles>C#COC(CCCNCCN)(OC)OC#C</smiles><smiles>COCCO</smiles><smiles>C#CO[Si](CCCNCCN)(OC#C)OC#C</smiles>

(a)

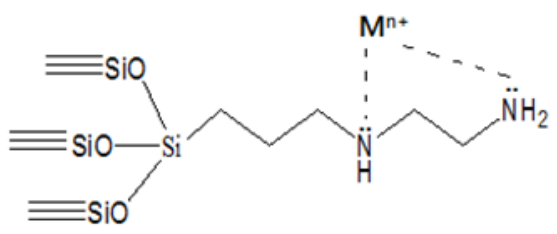

(b)

Figure 1. Schematic representation of (a) synthesis reaction of EDAPTMS-modification of silica, (b) schematic representation of EDAPTMS-metal interaction 
garding IUPAC classification, indicating the presence of micropores and mesopores in the materials. From BJH pore distribution it is seen that there is an evolution on dominant pore size from the variation of EDAPTMS content. Modification of silica with EDAPTMS slightly influence the adsorption profile in that the higher volume adsorbed is recorded in all relative pressure as well as the effect of EDAPTMS content to the adsorption-desorption profile. The pattern reflects the increasing specific surface area recapitulated in Table 1 . It is concluded that the modification creates more space to adsorb nitrogen and theoretically provide a greater surface for adsorption sites as one important parameter in the adsorption process. However, it is concluded that the higher the EDAPTMS content, the higher the specific surface area of the modified silica obtained. The formation of silica from EDAPTMS is potentially the reason for the trend.

The higher specific surface areas of the samples are in line with pore volume and pore radius parameters. From those data, it is assumed that grafting the silica structure by using EDAPTMS creates more space and porosity. The attachment of EDAPTMS to the silica is exhibited by FTIR spectra and presented in Figure 3, and the intensive peaks from the measurements are shown in Table 2.

The presence of silica is indicated by the $\mathrm{Si}-\mathrm{O}-\mathrm{Si}$ asymmetric stretching vibration at $1000-1250 \mathrm{~cm}^{-1}$ and $\mathrm{OH}$ bending vibration at around $799 \mathrm{~cm}^{-1}$. The presence of adsorption water was reflected by $v(\mathrm{OH})$ vibration around $3600 \mathrm{~cm}^{-1}$. Compared to free silica, the spec-
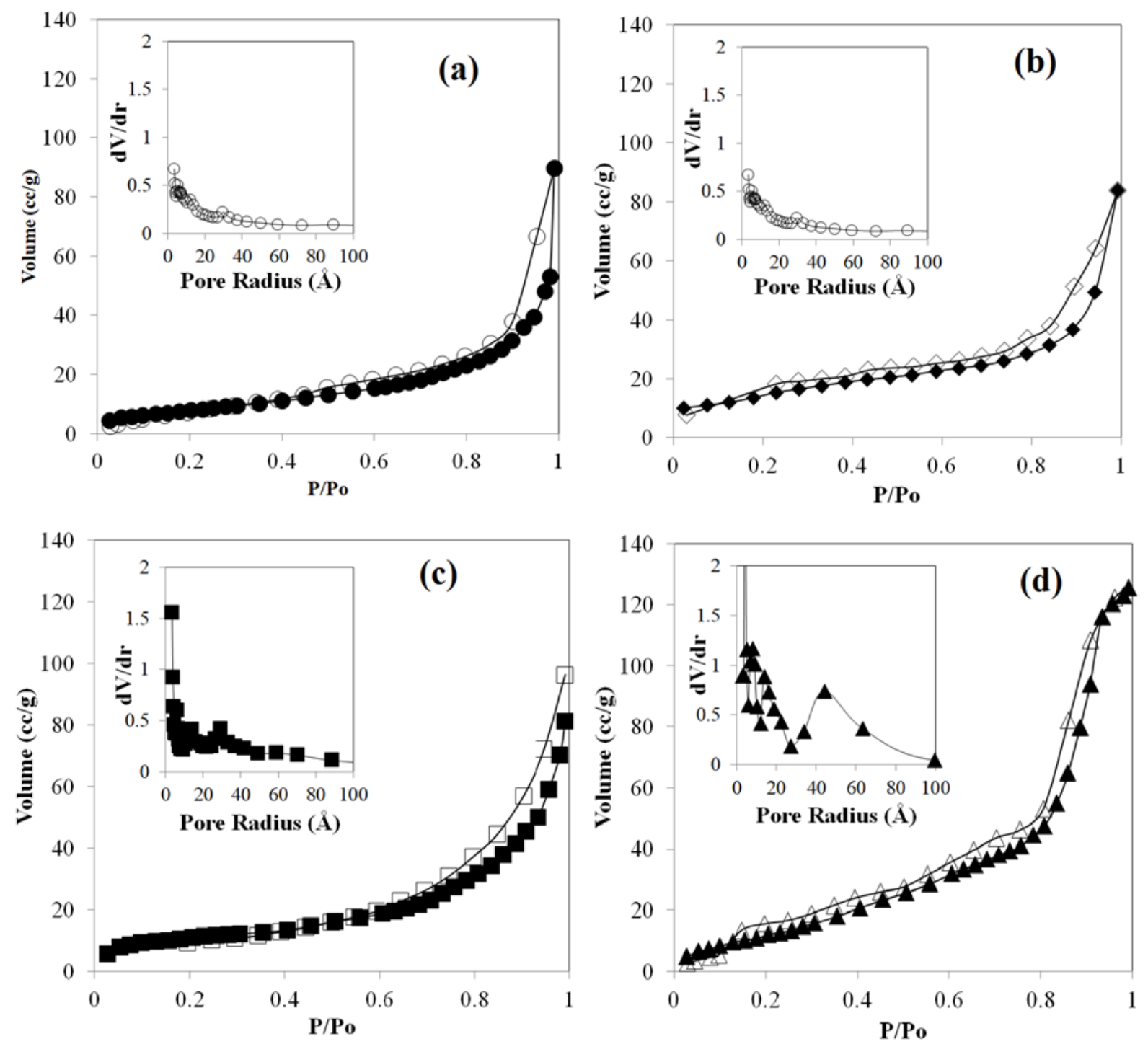

Figure 2. Adsorption-desorption profile of (a) silica, (b) EDAPTMS-Si-1, (c) EDAPTMS-Si-2, (d) EDAPTMS-Si-5 
trum of EDAPTMS-Si exhibits some new peaks such as the $\mathrm{CH}_{2}$ vibration band at 2360.84 $\mathrm{cm}^{-1}$. The presence of primary amine is identified from the spectra at around $1507.82 \mathrm{~cm}^{-1}$, which corresponds to the presence of the primary amine $\left(-\mathrm{NH}_{2}\right)$ from anchored EDAPTMS and at $1489 \mathrm{~cm}^{-1}$, which is attributed to the interaction of $-\mathrm{NH}_{2}$ with carbonate from air and form amine bicarbonate salt $\left(-\mathrm{NH}_{3}+\left(\mathrm{HCO}_{3}^{-}\right)\right)$. The spectra at $3350.30-3351.09 \mathrm{~cm}^{-1}$ found in EDAPTMS-Si- 2 and EDAPTMS-Si-5 are the indication of $-\mathrm{NH}_{2}$ stretching. The absence of this spectra in EDAPTMS-Si-1 is probably caused by the overlapping with the wide spectra of $-\mathrm{OH}$ from $\mathrm{Si}-\mathrm{OH}$ at range of $3030-3630 \mathrm{~cm}^{-1}$. These patterns are similar with those reported by previous research on zeolite and silica modification using 3-aminopropyltriethoxysilane $[18,19]$.

Furthermore, from XRD measurement (Figure 4) it is noticed that there is no significant change of silica amorphous phase reflection at $2 \theta$ around $22^{\circ}$ by EDAPTMS attachments. EDAPTMS modification demonstrates the effect on surface morphology as shown by SEM profile in Figure 5. The rougher surfaces are appeared for EDAPTMS-Si samples reflecting the formation of surface adsorption sites which is in line with the adsorption-desorption analyses results.

\subsection{Adsorption test}

Adsorption experiments of $\mathrm{Cu}(\mathrm{II}), \mathrm{Cr}(\mathrm{III})$, and $\mathrm{Pb}(\mathrm{II})$ in single and mixed solutions were conducted in a batch system. Compared with adsorption by using silica, the kinetics of adsorption of single solutions over EDAPTMS-Si1 provide the data represented in Figure 6.

From the curves, it is found that the adsorption rate of EDAPTMS-Si towards all ions is higher than that of $\mathrm{Si}$, as shown by the trend of adsorbed ion concentration at all varied times. The enhancement of the adsorption capability of silica by EDAPTMS modification is related to the possible interaction of ions in the solution with the amine functional group.

From the observed kinetics by EDAPTMS$\mathrm{Si}$, the adsorption of $\mathrm{Cr}$ (III) represents the highest rate compared with the other ions and the trend is as follows: $\mathrm{Cr}$ (III) $>\mathrm{Pb}$ (II) $>\mathrm{Cu}$ (II). From the kinetics of adsorption as a function of adsorption time, a pseudo-first-order and a pseudo-second-order kinetic model were simulated by following equation:

$$
\begin{gathered}
\ln \frac{q_{e}-q_{t}}{q_{e}}=-k_{1} t \\
\frac{1}{q_{e}-q_{t}}=\frac{1}{q_{e}}+k_{2} t
\end{gathered}
$$

Table 1. Specific surface area, pore volume and pore radius of materials

\begin{tabular}{lccc}
\hline Sample & Specific surface area $\left(\mathrm{m}^{2} / \mathrm{g}\right)$ & $\begin{array}{c}\text { Pore Volume } \times 10^{-3} \\
\left(\mathrm{~cm}^{3} / \mathrm{g}\right)\end{array}$ & Pore radius $(\AA)$ \\
\hline Si & 29.79 & 12.36 & 6.67 \\
EDAPTMS-Si-1 & 55.09 & 13.08 & 6.83 \\
EDAPTMS-Si-2 & 84.99 & 36.21 & 7.10 \\
EDAPTMS-Si-5 & 158.23 & 91.43 & 9.89 \\
\hline
\end{tabular}

\begin{tabular}{|c|c|c|}
\hline \multicolumn{2}{|c|}{$\begin{array}{l}\text { Vibrational functional groups for each material } \\
\qquad\left(\mathrm{cm}^{-1}\right)\end{array}$} & \multirow[t]{2}{*}{ Interpretation } \\
\hline $\mathrm{Si}$ & EDAPTMS-Si & \\
\hline & $3350.30-3351.09$ & Stretching of $-\mathrm{NH}$ \\
\hline 3600.2 & $3456.7-3650.90$ & Stretching of $-\mathrm{OH}$ of $\mathrm{Si}-\mathrm{OH}$ \\
\hline- & $2358.00-2360.84$ & Aliphatic chain of $-\mathrm{CH}_{2-}$ \\
\hline- & 1507.82 & $\mathrm{C}-\mathrm{N}$ vibration \\
\hline 1041.74 & 1084.8 & Asymmetric stretching $\mathrm{Si}-\mathrm{O}$ from $\mathrm{Si}-\mathrm{O}-\mathrm{Si}$ \\
\hline 802.3 & - & Symmetric stretching $\mathrm{Si}-\mathrm{O}$ from $\mathrm{Si}-\mathrm{O}-\mathrm{Si}$ \\
\hline 458.7 & 471.46 & Bending Si-O from $\mathrm{Si}-\mathrm{O}-\mathrm{Si}$ \\
\hline
\end{tabular}

Table 2. Interpretation of infrared spectra of materials 


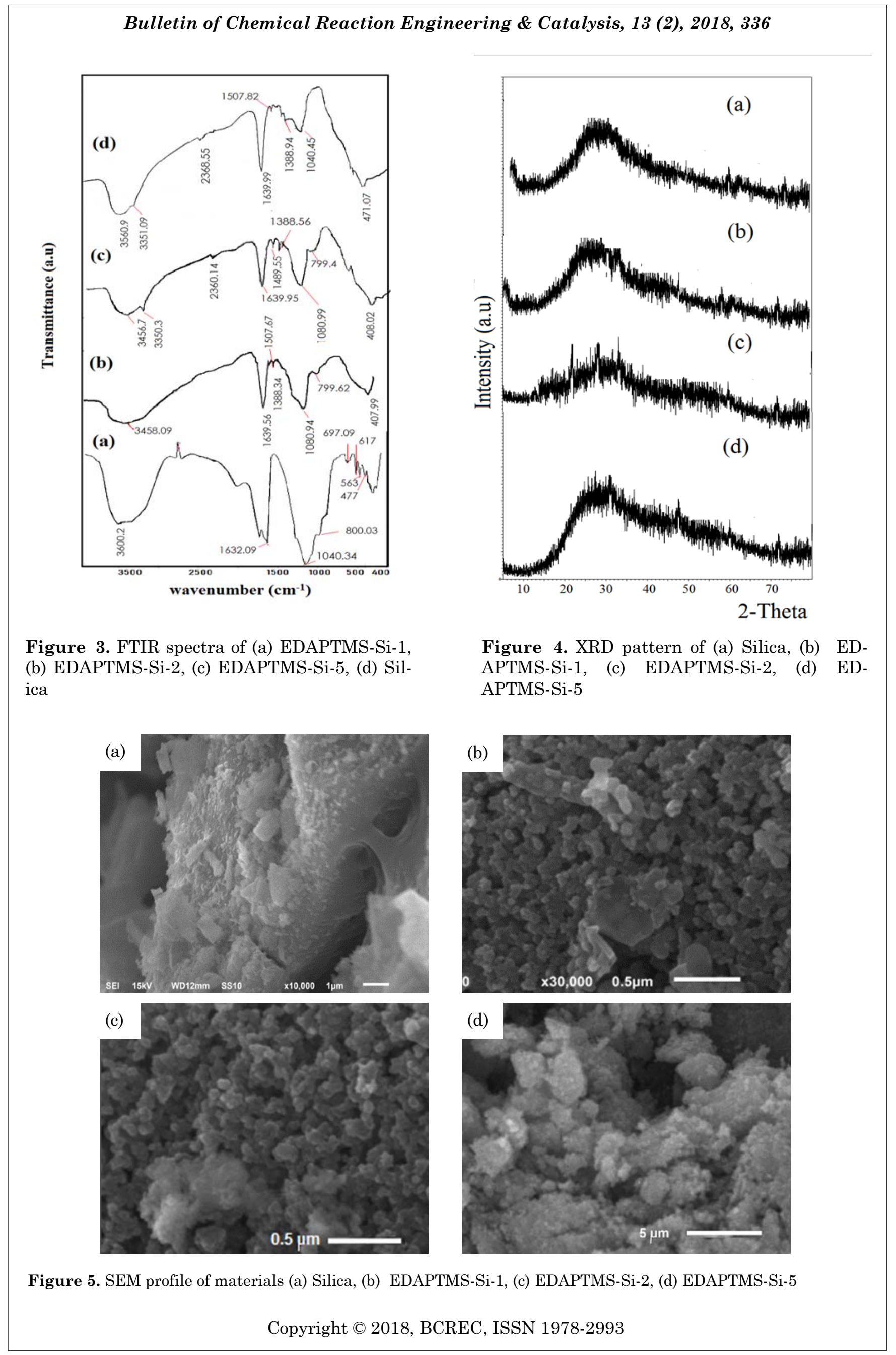


The parameters $q_{e}$ and $q_{t}$ are the calculated amounts of ion adsorbed per unit adsorbent at equilibrium and at time $t(\mathrm{~min}), k_{1}$ is the pseudo-first-order rate constant in the adsorption process, and $k_{2}$ is the rate constant for the pseudo-second order. The kinetics data are presented in Table 3.

From the data in Table 3, it can be concluded that the kinetics of all metal ion adsorption obey the pseudo-first-order kinetic model rather than the pseudo-second-order kinetic model due to the higher coefficient of correlation values among the variations. It means that the concentration of the metal solution is the only one factor affecting adsorption kinetics. By varying the initial concentration, the ratio of concentration at equilibrium condition $(C)$ to initial concentration $\left(C_{o}\right)$, it is seen that the higher initial concentration gives a higher result of metal ion in equilibrium. This trend is usually seen as an indication that the adsorption follows the equilibrium mechanism. The $q_{e}$ values gives pattern that the adsorption capacity of the samples are in following order: $\mathrm{Cr}$ (III) $>\mathrm{Cu}$ (II) $>\mathrm{Pb}$ (II). The trend is the proof that the presence of EDAPTMS modification on surface play role for the chemical interaction in the adsorption mechanism. The stronger chemical interaction obtained between $\mathrm{Cr}$ (III)
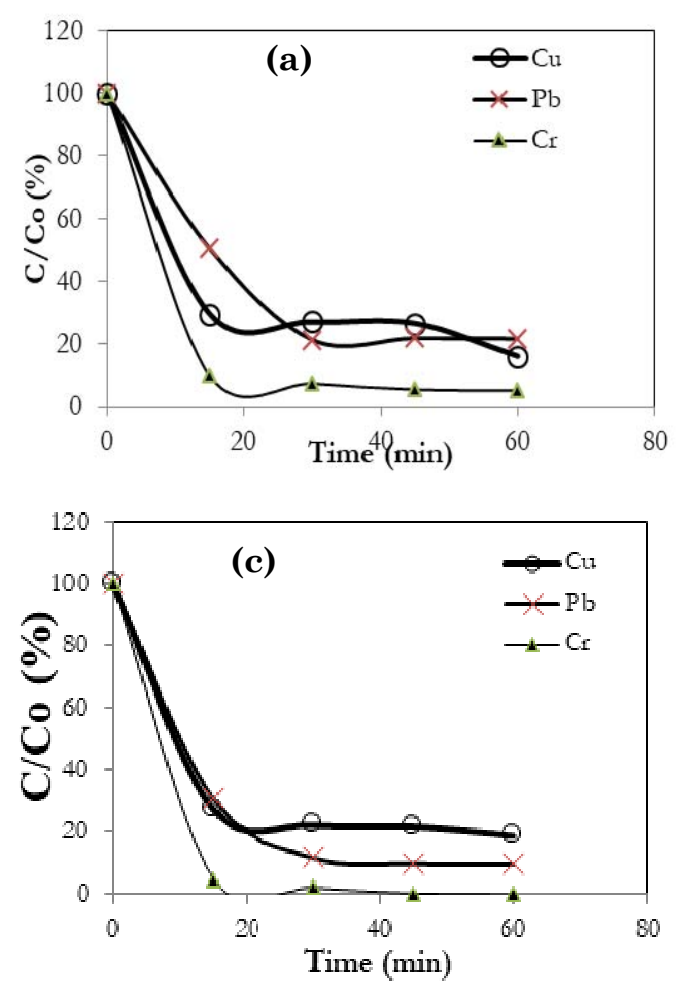

rather than other metal ions with ammine functional group on the adsorbent surface is due to the highest the ionic strength of $\mathrm{Cr}$ (III).

In order to study the mechanism, the Langmuir isotherm and Freundlich isotherm models were applied to the data by using equations ( 3 and 4).

$$
\begin{aligned}
\frac{C_{e}}{q_{e}} & =\frac{C_{e}}{q_{m}}+\frac{1}{K_{L} q_{m}} \\
\ln q_{e} & =\ln K_{F}+\frac{\ln C_{e}}{n}
\end{aligned}
$$

where $C_{e}$ is the equilibrium concentration of ions (mg. $\left.\mathrm{L}^{-1}\right)$ and $q_{e}$ is the amount of ions adsorbed by per gram adsorbent (mg.g-1). Meanwhile $q_{m}$ is the theoretical maximum adsorption capacity (mg.g-1) and $K_{L}$ is the adsorption energy (L.g-1), respectively. The $q_{m}$ and $K_{L}$ were calculated from the slope and the intercept of the linear line of $\mathrm{Ce} / q_{e}$ versus $C_{e}$, respectively.

Data obtained by the calculations are shown in Table 4. The data show that $\mathrm{Pb}$ (II) and Cr(III) adsorption fit the Freundlich isotherm better than the Langmuir isotherm, while for $\mathrm{Cu}(\mathrm{II})$, the Langmuir isotherm is more feasible when referring to the highest value of correla-
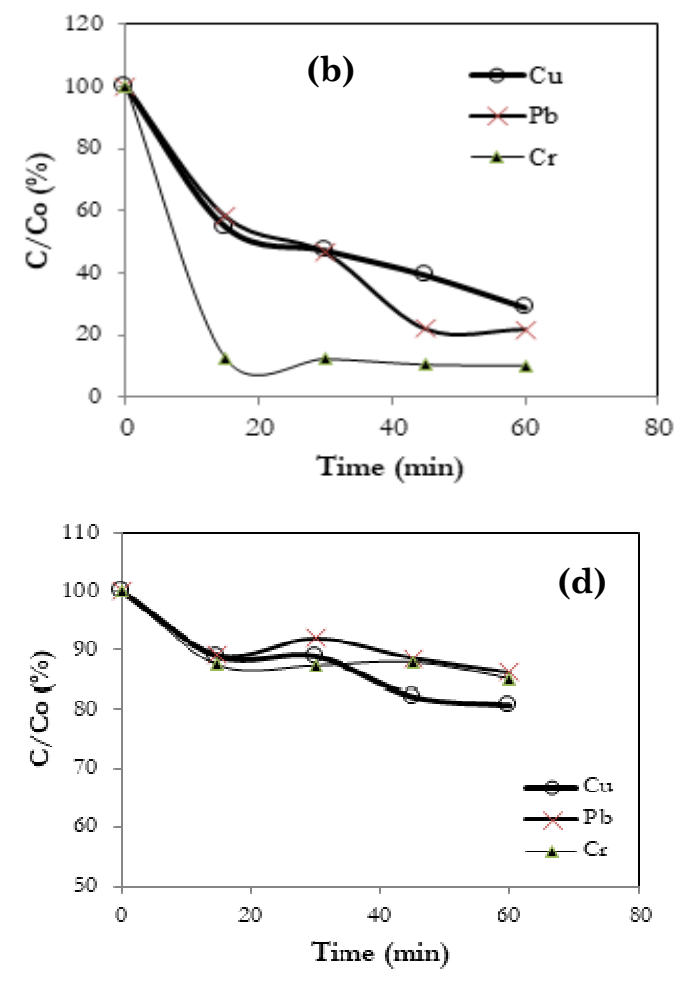

Figure 6. Effect of initial concentration on adsorptivity over a) EDAPTMS-Si-1, (b) EDAPTMS-Si-2, (c) EDAPTMS-Si-5, (d) silica 
tion coefficient. Furthermore, the kinetics of adsorption experiments were performed in a mixed solution system. The kinetics data provide the adsorption selectivity. From the rate of ion adsorption, the capability of modified silica was found to have $\operatorname{Cr}$ (III) adsorption at the highest rate, followed by $\mathrm{Pb}(\mathrm{II})$ and $\mathrm{Cu}(\mathrm{II})$. As EDAPTMS content varied, the trend on ions adsorption capacity did not change. However, Cr(III) adsorption capacity over the EDAPTMS-Si-5 pattern seems to have an equilibrium condition at initial concentration of 50 $\mathrm{mg} / \mathrm{L}$, while the pattern is not found in other EDAPTMS-Si materials. This may relate to the more alkyl functional groups producing a bulky condition to give coordination bonding between the $\mathrm{Cr}$ (III) ions. This assumption is also in line with the adsorption selectivity from the mixed solutions. For all concentrations, the trend of selectivity is in line with the kinetic adsorption in that the selectivity of $\mathrm{Cr}$ (III) is the highest, followed by $\mathrm{Pb}(\mathrm{II})$ and $\mathrm{Cu}(\mathrm{II})$. Generally, the selectivity of $\mathrm{Cr}$ (III) decreased as the initial con- centration increased (Figure 6). This reflects the ion competition at the higher concentration in the mixed solution system. From the varied EDAPTMS content, it is noted that the selectivity towards $\mathrm{Cr}$ (III) adsorption by EDAPTMS-Si-1 is the highest, while EDAPTMSSi-2 and EDAPTMS-Si-5 have similar values. It is concluded that the interaction between ions and EDAPTMS was affected by the presence and the content of the amine functional group of adsorbents (Figure 7). It is predicted that the EDAPTMS-Si-2 and EDAPTMS-Si-5 will give similar interaction intensities. The ranges of adsorbed ions are similar to the results from previous research on adsorption over modified silica [18,20].

\subsection{Effect of $\mathrm{pH}$}

The effect of the $\mathrm{pH}$ of the solution on the adsorptivity is one important aspect with regard to the affecting parameter in the adsorption application on an industrial scale. The ef-

Table 3. Kinetics data of metal adsorption in single solution

\begin{tabular}{|c|c|c|c|c|c|}
\hline \multirow[t]{2}{*}{ Sample } & \multirow[t]{2}{*}{ Metal Ion } & \multicolumn{3}{|c|}{ Pseudo-first-order kinetic model } & \multirow{2}{*}{$\begin{array}{l}\text { Pseudo-second or- } \\
\text { der kinetic model } \\
\mathrm{R}^{2}\end{array}$} \\
\hline & & $\mathrm{R}^{2}$ & $k_{1}$ & $q_{e}$ & \\
\hline \multirow[t]{3}{*}{ EDAPTMS-Si-1 } & $\mathrm{Cu}(\mathrm{II})$ & 0.9931 & 0.0154 & 0.0197 & 0.8557 \\
\hline & $\mathrm{Pb}(\mathrm{II})$ & 0.8922 & 0.0165 & 0.0114 & 0.8003 \\
\hline & $\mathrm{Cr}(\mathrm{III})$ & 0.9973 & 0.1343 & 0.1003 & 0.9334 \\
\hline \multirow[t]{3}{*}{ EDAPTMS-Si-2 } & $\mathrm{Cu}(\mathrm{II})$ & 0.9731 & 0.0188 & 0.0288 & 0.9653 \\
\hline & $\mathrm{Pb}(\mathrm{II})$ & 0.8702 & 0.0265 & 0.0137 & 0.8199 \\
\hline & $\mathrm{Cr}(\mathrm{III})$ & 0.9953 & 0.1616 & 0.1172 & 0.9594 \\
\hline \multirow[t]{3}{*}{ EDAPTMS-Si-5 } & $\mathrm{Cu}(\mathrm{II})$ & 0.9934 & 0.0344 & 0.0317 & 0.9098 \\
\hline & $\mathrm{Pb}(\mathrm{II})$ & 0.8902 & 0.0325 & 0.0149 & 0.8599 \\
\hline & $\mathrm{Cr}(\mathrm{III})$ & 0.9953 & 0.2546 & 0.2223 & 0.9023 \\
\hline
\end{tabular}

Table 4. Data of Langmuir and Freundlich isotherm

\begin{tabular}{lccccc}
\hline & \multirow{2}{*}{ Metal Ion } & \multicolumn{2}{c}{ Langmuir Isotherm } & & \multicolumn{2}{c}{ Freundlich Isotherm } \\
\cline { 5 - 6 } \cline { 5 - 6 } & & $\mathrm{R}^{2}$ & & $\mathrm{R}^{2}$ & $\mathrm{KF}$ \\
\hline EDAPTMS-Si-1 & $\mathrm{Cu}(\mathrm{II})$ & 0.9881 & & 0.9674 & 5.899 \\
& $\mathrm{~Pb}(\mathrm{II})$ & 0.9901 & & 0.9779 & 5.543 \\
& $\mathrm{Cr}(\mathrm{III})$ & 0.9799 & & 0.9452 & 6.752 \\
\hline EDAPTMS-Si-2 & $\mathrm{Cu}(\mathrm{II})$ & 0.9854 & & 0.9844 & 5.902 \\
& $\mathrm{~Pb}(\mathrm{II})$ & 0.9852 & & 0.9892 & 5.523 \\
& $\mathrm{Cr}(\mathrm{III})$ & 0.9836 & & 0.9952 & 6.442 \\
\hline EDAPTMS-Si-5 & $\mathrm{Cu}(\mathrm{II})$ & 0.9884 & & 0.9489 & 6.019 \\
& $\mathrm{~Pb}(\mathrm{II})$ & 0.9880 & & 0.9782 & 6.423 \\
& $\mathrm{Cr}(\mathrm{III})$ & 0.9757 & & 0.9711 & 6.982 \\
\hline
\end{tabular}


fect of the $\mathrm{pH}$ is also seen to enhance the adsorption rate by increasing the $\mathrm{pH}$ of the solution (Figure 8). The results were conducted with control samples of the solution without the addition of any adsorbents to ensure that metal precipitation did not occur. Considering the previous report, the presence of hydroxyl in the solution contributes to enhancing the activity of the amino functional group, and the interaction of the amine functional group is effectively developed by the $\mathrm{pH}$ condition up to 3 [21].

\section{Conclusion}

Functionalized silica-based adsorbent obtained from rice husk ash modified with ethylene diamine aminopropyl trimethoxy silane (APTMS), namely EDAPTMS, was successfully prepared. The specific surface area of the silica was increased after the modification. From the adsorption experiments of $\mathrm{Cr}(\mathrm{III}), \mathrm{Cu}(\mathrm{II})$, and $\mathrm{Pb}$ (II) solutions, it was found that the modification enhances metal adsorption in both single and mixed solutions. The selectivity of metal ions is as follows: $\mathrm{Cr}(\mathrm{III})>\mathrm{Pb}$ (II) $>\mathrm{Cu}$ (II). The adsorption obeys the Freundlich isotherm and is affected by the $\mathrm{pH}$ of the system.
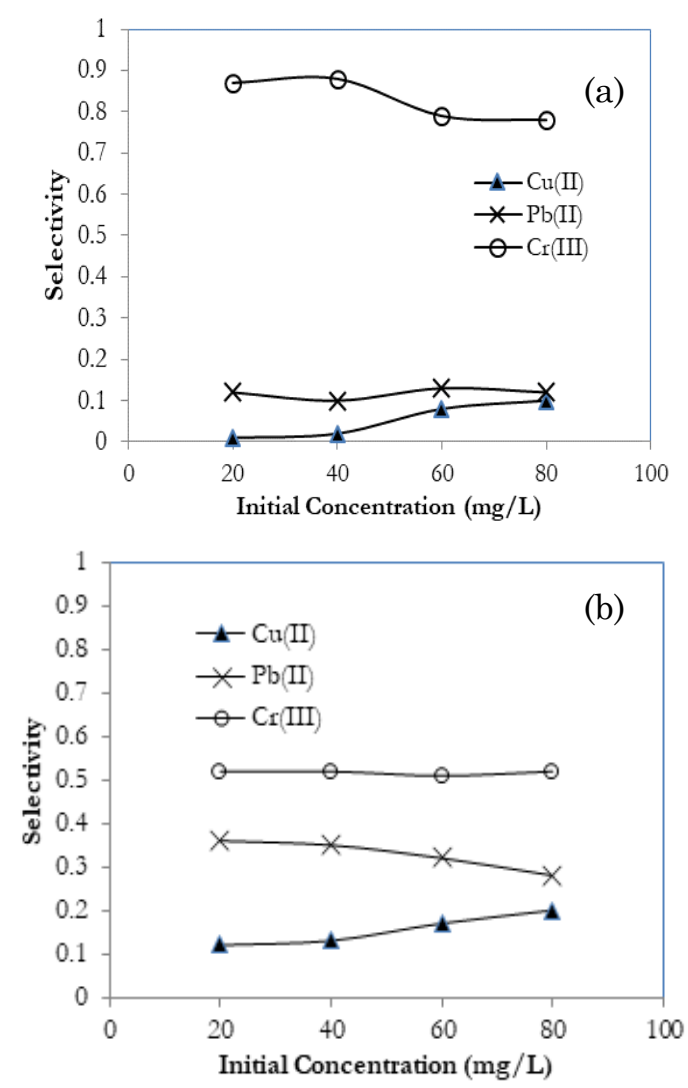

\section{Acknowledgment}

The authors wish to thank the Chemistry Department for research funding under Contract No. 001/PenProdi/2016.

\section{References}

[1] Samiey, B., Cheng, C., Wu, J. (2014). Organic-inorganic Hybrid Polymers as Adsorbents for Removal of Heavy Metal Ions from Solutions: A Review. Materials (Basel). 7: 673-726.

[2] Lam, K.F., Yeung, K.L., Mckay, G., Program, E.E. (2005). Gold Removal and Recovery using Mesoporous Silica Adsorbents, The Hong Kong University of Science and Technology (HKUST) Post-modification, 2: 273-276.

[3] Yang, H., Xu, R., Xue, X., Li, F., Li, G. (2008). Hybrid Surfactant-templated Mesoporous Silica Formed in Ethanol and Its Application for Heavy Metal Removal. J. Hazard. Mater., 152: 690-698.

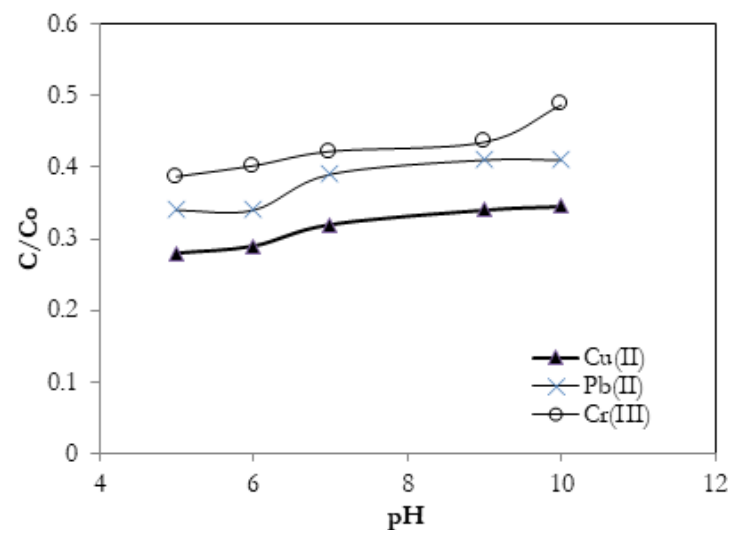

Figure 8. Effect of $\mathrm{pH}$ on adsorption (initial concentration $=40 \mathrm{ppm}$, adsorbent $=$ EDAPTMS-Si-1)

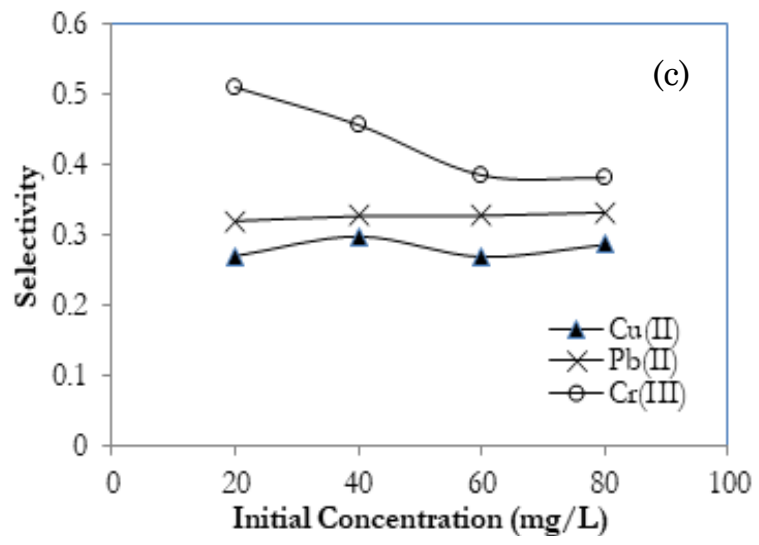

Figure 7. Selectivity of metal ion adsorptivity in mixed solution over (a) EDAPTMS-Si-1, (b) EDAPTMS-Si-2, (c) EDAPTMS-Si-5 
[4] Radi, S., Tighadouini, S., Bacquet, M., Degoutin, S., Cazier, F., Zaghrioui, M., Mabkhot, Y. (2013). Organically Modified Silica with Pyrazole-3-carbaldehyde as a New Sorbent for Solid-Liquid Extraction of Heavy Metals. Molecules, 19: 247-262.

[5] Radi, S., Basbas, N., Tighadouini, S. (2013). New Amine-modified Silicas: Synthesis, Characterization and Its Use in the $\mathrm{Cu}$ (II)Removal from Aqueous Solutions, Progress in Nanotechnology and Nanomaterials, 2: 108116.

[6] Kishor, R., Ghoshal, A.K. (2015). APTES Grafted Ordered Mesoporous Silica KIT-6 for $\mathrm{CO}_{2}$ Adsorption. Chem. Eng. J., 262: 882-890.

[7] Wang, S., Wang, K., Dai, C., Shi, H., Li, J. (2015). Adsorption of $\mathrm{Pb}^{2+}$ on Aminofunctionalized core-shell Magnetic Mesoporous SBA-15 Silica Composite. Chem. Eng. J., 262: 897-903.

[8] Tu, S., Lv, F., Hu, P., Meng, Z., Ran, H., Zhang, Y. (2015). Colloids and Surfaces A: Physicochemical and Engineering Aspects Preparation of Amine-modified Silica Foams and their Adsorption Behaviors toward TNT Red Water. Colloids Surfaces A Physicochem. Eng. Asp., 481: 493-499.

[9] Belhaj, S., Takagaki, A., Sugawara, T., Kikuchi, R. (2015). Alkylamine - silica Hybrid Membranes for Carbon Dioxide/Methane Separation. J. Memb. Sci., 477: 161-171.

[10] Suzuki, S., Belhaj, S., Takagaki, A., Sugawara, T. (2014). Development of Inorganicorganic Hybrid Membranes for Carbon Dioxide/Methane Separation. J. Memb. Sci., 471: 402-411.

[11] Diagboya, P.N., Olu-owolabi, B.I., Adebowale, K.O. (2014). Microscale Scavenging of Pentachlorophenol in Water Using Amine and Tripolyphosphate-grafted SBA-15 Silica: Batch and Modeling Studies, J. Environ. Manag., 146: $42-49$.

[12] Suriyanon, N., Punyapalakul, P., Ngamcharussrivichai, C. (2015). Synthesis of Periodic Mesoporous Organosilicas Functionalized with Different Amine-organoalkoxysilanes via Direct Co-condensation. Mater. Chem. Phys., 149-150: 701-712.
[13] Della, V., Kuhn, I., Hotza, D. (2002). Rice Husk Ash as an Elemente Source for Active Silicaproduction. Mater. Lett., 57: 818-821.

[14] Kalapathy, U., Proctor, A., Shultz, J. (2002). An Improved Method for Production of Silica from Rice Hull Ash. Bioresour. Technol., 85: 285-289.

[15] Yalçin, N., Sevinç, V. (2001). Studies on Silica Obtained from Rice Husk. Ceram. Int., 27: 219-224.

[16] Fatimah, I., Said, A., Hasanah, U.A. (2015). Preparation of $\mathrm{TiO}_{2}-\mathrm{SiO}_{2}$ using Rice Husk Ash as Silica Source and the Kinetics Study as Photocatalyst in Methyl Violet Decolorization. Bull. Chem. React. Eng. Catal., 10: 4349.

[17] Terracciano, M., Rea, I., Politi, J., De Stefano, L. (2013). Optical Characterization of Aminosilane-modified Silicon Dioxide Surface for Biosensing. J. Eur. Opt. Soc., 8: 1-6.

[18] Cui, Y., Chang, X., Zhu, X., Luo, H., Hu, Z., Zou, X., He, Q. (2007). Chemically Modified Silica Gel with P-Dimethylaminobenzaldehyde for Selective Solid-Phase Extraction and Preconcentration of $\mathrm{Cr}$ (III), $\mathrm{Cu}(\mathrm{II}), \mathrm{Ni}(\mathrm{II}), \mathrm{Pb}$ (II) and $\mathrm{Zn}(\mathrm{II})$ by ICP-OES. Microchem. J., 87: 20-26.

[19] Budnyak, T., Tertykh, V., Yanovska, E. (2014). Chitosan Immobilized on Silica Surface for Wastewater Treatment. Mater. Sci., 20: $177-182$.

[20] Dai, J., Ren, F.L., Tao, C. (2012). Adsorption of $\mathrm{Cr}(\mathrm{VI})$ and Speciation of $\mathrm{Cr}(\mathrm{VI})$ and $\mathrm{Cr}(\mathrm{III})$ in Aqueous Solutions Using Chemically Modified Chitosan. Int. J. Environ. Res. Public Health, 9: 1757-1770.

[21] Huang, A., Wang, N., Caro, J. (2012). Seeding-free Synthesis of Dense Zeolite FAU Membranes on 3-Aminopropyltriethoxysilane-functionalized Alumina Supports. $J$. Memb. Sci., 389: 272-279. 